\title{
CONCEPÇÃO CONSTRUTIVISTA PERMEADA PELO USO DE TECNOLOGIAS: UM ESTUDO DE CASO
}

\author{
José Wilson da COSTA ${ }^{1}$ \\ Mariana Bethonico Muniz GUIMARÃES ${ }^{2}$ \\ Márcia Gorett Ribeiro GROSSI ${ }^{3}$
}

RESUMO: Diferentes tecnologias estão presentes nos contextos escolares e dependendo da maneira como são usadas, podem favorecer a construção do conhecimento. Para entender como as concepções construtivistas contribuem para a aprendizagem permeada pelo uso de tecnologias, foram investigados os impactos das tecnologias digitais da informação e comunicação (TDICs) na prática pedagógica construtivista. Trata-se de um estudo de caso em uma escola construtivista de Belo Horizonte - Minas Gerais, usando um ambiente virtual de aprendizagem (AVA) em uma disciplina optativa. Verificou-se que o uso das TDICs ultrapassa os conhecimentos construídos na escola, favorecendo o processo de ensino e aprendizagem. Assim o AVA pode ser considerado uma proposta educacional, pois proporciona uma aprendizagem colaborativa e mediada por diversos sujeitos sociais que atuam efetivamente para a construção do conhecimento.

PALAVRAS-CHAVE: Conhecimento. Tecnologias Digitais da Informação e Comunicação (TDICs). Construtivismo e prática pedagógica.

\section{Introdução}

As constantes transformações da sociedade, que hoje está sendo chamada de sociedade da informação ou do conhecimento e que é caracterizada pela inovação tecnológica, repercutiram em alterações significativas em diversos segmentos sociais, dentre eles a educação. Para Moore (1999) é difícil definir a sociedade da informação, mas: “[...] é possível descrever características comuns a esta sociedade. Contudo, traz o entendimento de que Sociedade de Informação é uma sociedade na qual a informação é utilizada intencionalmente, como elemento da vida econômica, social, cultural e política". (MOORE, 1999, p.97).

Com isso, percebe-se a importância da educação em acompanhar e intervir criticamente no que lhe concerne nessa nova ordem mundial que tem como uma de suas principais características a utilização das Tecnologias digitais da informação e comunicação (TDICs), como forma de propagação de serviços e informações em âmbito

${ }^{1}$ PUC - Pontifícia Universidade Católica de Minas Gerais. Professor Doutor do Programa de Pós Graduação em Educação. Belo Horizonte - MG - Brasil. 30535-901 - jwcosta01@ gmail.com.

${ }^{2}$ CEFET - Centro Federal de Educação Tecnológica de Minas Gerais. Mestre em Educação Tecnológica. Belo Horizonte - MG - Brasil. 30510-000 - marianabmg@ hotmail.com.

${ }^{3}$ CEFET - Centro Federal de Educação Tecnológica de Minas Gerais. Professora Doutora do Mestrado em Educação Tecnológica. Belo Horizonte - MG - Brasil. 30510-000 - marciagrossi@ terra.com.br. 
mundial. Inclusive sendo, estas tecnologias, incorporadas no processo de ensino e aprendizagem há algum tempo, em todas as modalidades da educação e em diferentes espaços escolares.

Neste sentido, concepções atuais de processo de conhecimento permitem compreender a aprendizagem para além dos ambientes escolares, a partir da incorporação dos espaços virtuais no estabelecimento de ações, relações e interações entre alunos e professores e, de alguma forma, questionar as antigas abordagens de ensinar e aprender e utilizando as novas tecnologias a favor da educação. Vários ambientes virtuais de aprendizagem têm sido utilizados no contexto educativo, como tentativa de romper as paredes da sala de aula e possibilitar a ocorrência da aprendizagem de forma mais significativa e dinâmica.

Segundo Weinberg (2008) o potencial das tecnologias digitais deve ser utilizado para modificar o quadro atual de divisão do conhecimento em áreas estanques, às vezes quase incomunicáveis e para desenvolver habilidades e competências em vez de treinar os alunos para a execução de tarefas repetitivas. Também Tapscott (2010) corrobora com essa ideia quando afirma que:

\begin{abstract}
Aprender uma maneira totalmente nova de se comunicar, acessar informações e se divertir é uma tarefa árdua, e nossos padrões estabelecidos de raciocínio devem mudar para acomodar a nova tecnologia. Para que essa mudança se estabeleça entre os docentes, é preciso esforço pessoal, capacitação profissional e incentivo estatal. (TAPSCOTT, 2010, p.30).
\end{abstract}

Além da necessidade de estarem capacitados para manusear e empregar as TDICs de maneira consciente e eficiente no processo de ensino e aprendizagem, os professores enfrentam mais um desafio: lidar com os alunos da geração Internet, que estão inseridos em um contexto onde a informação é distribuída em variadas mídias, em tempo real, de fácil acesso e disponível em praticamente todos os lugares, principalmente com a presença dos telefones e computadores móveis, como explicado por Tepedino (2004, p.18):

Estamos na era da informação e a cada dia os alunos têm mais fontes de informações ao seu alcance. Entretanto, eles precisam da ajuda dos professores para aprender a interpretar a enorme quantidade de informações que recebem. Os conteúdos se renovam constantemente e as crianças e os adolescentes conquistaram um novo espaço, também são cidadãos de um ciberespaço. Eles sabem operar os computadores 
melhor do que muitos adultos. Essa nova realidade requer um professor capacitado para lidar com as tecnologias e que possa assumir novos papéis na escola da Sociedade da Informação.

Nesta perspectiva, este estudo teve como objetivo investigar os impactos das tecnologias digitais da informação e comunicação na prática pedagógica construtivista, por meio de um estudo de caso.

\section{A utilização das tecnologias a favor do conhecimento: mudanças básicas do ensino presencial}

Cada ser humano percebe o mundo de modo diferente e constrói a realidade à sua maneira. A apropriação dessa realidade, a construção de significados, o compartilhamento das percepções pessoais com outros sujeitos e a adaptação a novos contextos, constituem o processo de construção do conhecimento. Ensinar vai além de transmitir conteúdo e informação, resulta do entendimento que se faz das interações com o meio ambiente (JONASSEN, 1996). Permite desde a interação entre professor e aluno, entre os próprios alunos e a interação entre os alunos e o conteúdo.

$\mathrm{Na}$ atualidade, esse processo se ancora, cada vez mais, nos contextos elaborados pelas telecomunicações e pela informática (LÉVY, 1993) nos quais o sujeito aprende permeado de informações que chegam a qualquer hora e de qualquer lugar do mundo, transformando as práticas tradicionais de conviver, trabalhar, educar e até mesmo de pensar e adquirir conhecimento, influenciando diretamente no processo educacional, como explica Coscarelli (2002, p.52):

[...] além de influenciar algumas atividades elementares do cotidiano do sujeito contemporâneo, a informática também interfere na forma como ele lida com a informação necessária à sobrevivência. Por meio dos recursos dessa tecnologia, a recuperação, o armazenamento, a organização, o tratamento, a produção e a disseminação da informação tornam-se tarefas cada vez mais incorporadas à realidade desse sujeito.

Costa e Paim (2004) ampliam a reflexão sobre o contexto informacional, para eles a informação, o conhecimento, o saber e a aprendizagem são indissociáveis do processo educativo. E, dependendo da forma como a tecnologia da informação for utilizada, potencializará esse processo e, sabe-se que uso das tecnologias na prática de ensino não é recente. A implementação de programas e políticas públicas que objetivam a adoção e a 
integração de ferramentas no contexto educacional brasileiro está, segundo Mendonça (2010), presente há algumas décadas.

É o caso da internet que chegou visivelmente no início da década de 80 e vem viabilizando a implementação de cursos à distância permitindo o encontro de professores e alunos não somente em salas de aula como também através de redes, provocando a revisão da estrutura disciplinar e mudanças básicas do ensino presencial brasileiro. A Lei n ${ }^{\circ}$ 9.394, de 20 de dezembro de 1996, conhecida como Lei de Diretrizes e Bases (LDB) (BRASIL, 1996), amplia a dimensão axiológica do termo educação colocando-o em um sentido abrangente, tratando não apenas da educação formal, a não-formal, a continuada, a ambiental e outras já conhecidas, como também da educação a distância.

Assim, na década de 90 com a LDB (BRASIL, 1996), percebe-se claramente a necessidade do ensino mediado pela tecnologia, incorporando o ensino a distância ao presencial. Carneiro (1998) aponta no Art. 32, parágrafo $4^{\circ}$ da LDB (BRASIL, 1996, grifos do autor), que como complementação da aprendizagem ou em situações emergenciais o Ensino Fundamental poderá ser à distância e reflete sobre a conseqüente ampliação das possibilidades de acesso ao Ensino Fundamental (sendo democratizante), incluindo a instrumentação eletrônica nos materiais de apoio ao ensino (sendo moderna), agilizando a aprendizagem daqueles alunos que não tiveram acesso à escola na idade própria (sendo compensatória) e reduzindo a distorção idade/série (sendo reequacionadora).

Estudos também apontam os impactos das TDICs no processo ensino e aprendizagem e refletem sobre a importância de conhecer as tecnologias presentes no contexto educacional e repensar as estratégias e concepções de ensino. Para Moran (2003) os modelos tradicionais de ensino são cada vez mais inadequados, por isso, professores e alunos são desafiados a encontrar novos modelos para novas situações, não se limitando ao trabalho dentro de sala de aula. Segundo este autor poucas adaptações e pequenas mudanças são feitas diante às grandes possibilidades das redes eletrônicas.

Grispun (2002) afirma que a educação do mundo de hoje tende a ser tecnológica, exigindo entendimento e interpretação de tecnologias. A autora acredita que não há como separar tecnologia de educação. Quanto às ações educativas Coscarelli (2002, p.26) acredita que estas: 
aprender. Além disso, é necessário levar em conta o alto nível de variedade em relação aos estilos e maneiras de aprender, interesses e motivação de um grupo de alunos.

Rezende $(2002)^{4}$ também acredita no papel ativo no ato de aprender e aponta aspectos relevantes como, por exemplo, a simulação, como possibilidade de interação do aluno com a realidade e o impacto do construtivismo sobre os ambientes informatizados de aprendizagem. Sugere a aprendizagem do aluno por meio das interações, inclusive com os materiais didáticos que, incorporados às novas tecnologias passam para a mão do estudante o controle de sua aprendizagem. Enfatiza que para a interação do aluno com esses materiais é necessário que ele adquira a consciência do que consiste aprender (metacognição), pois assim ele perceberá o conteúdo não visando apenas à avaliação. Para Valente (apud REZENDE, 2002), quanto à utilização da Internet no processo educativo, o professor deixa de ser o repassador do conhecimento para ser o criador de ambientes de aprendizagem e facilitador do processo pelo qual o aluno adquire conhecimento.

Nessa perspectiva Oliveira, Costa e Moreira (2004) afirmam que a presença das tecnologias no processo de ensino e aprendizagem abre espaço para se repensar o fazer pedagógico e numa abordagem interacionista, proposta por Vygotsky, possibilita a formação de um sujeito (aluno) mais autônomo, capaz de enfrentar os desafios que a construção do conhecimento proporciona e contribuir para a formação das competências necessárias para que os jovens venham a ter uma inserção social adequada.

Esses autores apontam a escola como o lugar principal para isso, uma vez que tem a possibilidade de permitir a efervescência de ambientes concretizados em várias dimensões e, dependendo das concepções de conhecimento e aprendizagem assumidas pelo professor, permite a aprendizagem de conteúdos, atitudes, habilidades e, consequentemente, o desenvolvimento de esquemas cognitivos. Destaca-se neste trabalho a concepção construtivista, em que o indivíduo é considerado sujeito ativo de seu próprio conhecimento.

\section{O construtivismo para além da escola}

\footnotetext{
${ }^{4}$ A autora apresenta estudos nas literaturas nacional e estrangeira sobre a utilização das novas tecnologias da informação e comunicação no processo educativo sob a perspectiva construtivista.
} 
O termo construtivismo foi usado pela primeira vez nos anos 70 por Piaget, embora seus primeiros trabalhos terem sido publicados anos antes, em 1950. Piaget (1896-1980) e Vygotsky (1896-1934) são os principais representantes da concepção interacionista construtivista e explicam o conhecimento mediante a participação tanto do sujeito quanto dos objetos do conhecimento, “[...] que são mais ricas do que os objetos podem fornecer por eles mesmos" (PIAGET, 1980, p.87), constituindo-se num entrelaçar entre fatores internos (maturação) e os fatores externos (ações do meio). Assim como as abordagens maturacionistas, Piaget enfatiza o processo de desenvolvimento como objeto de estudo e enfatiza o papel dos fatores internos, como a maturação ou a equilibração, na determinação desse processo e que a construção do conhecimento vai depender tanto do meio físico como das condições do meio.

Já o enfoque de Vygotsky (2007) sugere que tanto o desenvolvimento quanto a aprendizagem são consequências das condições sociais em que o indivíduo está imerso, abordando assim, a perspectiva histórico-cultural e afirma que o meio social é determinante do desenvolvimento humano e que isso acontece pela aprendizagem da linguagem. Tanto Piaget como Vygotsky contribuíram para aproximarem os educadores do desenvolvimento da atividade da criança, para compreenderem seus processos de elaboração conceitual e para perceberem as relações que estabelecem com outras crianças e com os adultos. Tais atitudes dos educadores podem ajudar no entendimento de outra relação: a do ensino mediado pela tecnologia. Essa mediação não deve ser entendida como solução às práticas educacionais que insistem em reproduzir conhecimento, mas como possibilidade de realmente incluir professores e alunos na construção significativa do conhecimento.

Segundo Fontana e Cruz (1997) o modo como o professor lida com a prática educativa é determinado pela compreensão que ele tem sobre ela, podendo estar instrumentalizada e mediada pela teoria, ajudando-o a compreender o que ocorre em sala de aula, marcando suas decisões e modos de agir. Essa transferência da teoria para a prática, de usar os pressupostos construtivistas no cotidiano escolar para mediar o processo de aquisição de conhecimento, não é fácil e nem acontece de forma espontânea.

Isso porque é importante considerar como os professores e até mesmo os pais aprenderam e aprendem, entender que a ideia de colocar o indivíduo como sujeito ativo de seu próprio conhecimento é recente e, como afirma Macedo (2005) os professores de hoje querem aprender e não só ensinar, exigindo-lhes observação e reflexão sobre suas ações, novas competências em sua formação. 
Segundo Macedo (2005) o construtivismo é uma visão do conhecimento, os adultos têm o poder e o dever de transmitir de modo informal, no cotidiano da casa ou da vida, ou formal, no contexto da escola, o que crianças e jovens precisam aprender (PEROZIN, 2011). O construtivismo se opõe a um modo positivista e considera não só as intervenções do meio e as condições hereditárias, como também a integração com a qualidade da experiência e um processo de autoregulação que integra essas três características, conforme ilustrado na figura 1.

Figura 1: Esquema dos elementos que influenciam na construção do conhecimento

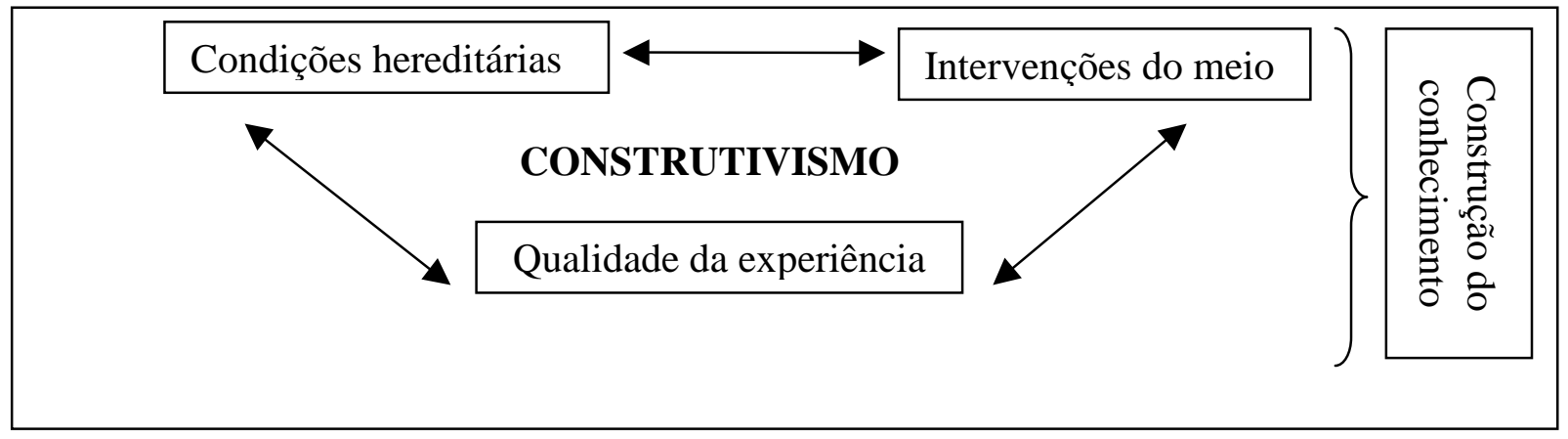

Fonte: Elaboração própria, baseada em Perozin (2011).

É, assim, uma proposta teórica e metodológica que pode e deve ser praticada de vários e diferentes modos, permitindo interagir, rever e incrementar estratégias de ensino, criar diferentes ambientes para a aprendizagem, permitir a troca de informação e de experiência. Um bom exemplo disso é a utilização dos ambientes virtuais de aprendizagem (AVAs) nas escolas, destacando-se como uma promissora proposta pedagógica. Dessa forma, Amaral e Rossine (2008 apud GOMES, 2001, p.25) classificao como:

\footnotetext{
Ambiente virtual de aprendizagem é o ambiente tecnológico no ciberespaço que permite o processo de ensino aprendizagem através da medição pedagógica entre alunos ou um grupo de alunos e o professor ou um grupo de professores ou de outros agentes geograficamente dispersos. Apresenta-se em formas de portais, banco de dados, bibliotecas virtuais, cursos a distancia, museus ou outros.
}

Outros autores também definem este conceito. De acordo com Silva (2009) os AVA's podem ser denominados como: 
Ambientes virtuais de aprendizagem são sistemas computacionais disponíveis na Internet, destinados ao suporte de atividades mediadas por tecnologias de informação e comunicação. Permitem integrar múltiplas mídias, linguagens e recursos, além disso, apresentam informações de maneira organizada, ampliam as interações entre as pessoas e objetos de conhecimento, propiciam ainda a socialização de experiências e produções. (SILVA, 2009, p.3).

Para Costa (2007), os AVAs constituem um espaço que permite o desenvolvimento das relações com o saber mediadas pelas tecnologias. No âmbito da escola, são desenvolvidas através de interações dos alunos com os conteúdos, dos alunos com outros alunos, dos alunos com os professores, sob a influência do seu meio afetivo e social, tanto dentro como fora da escola.

Pensando nisso, investigou-se a utilização de um AVA em uma escola construtivista com o propósito de verificar como acontece na prática o processo de construção do conhecimento.

\section{Metodologia}

Para atingir o objetivo deste estudo foi realizado um estudo de caso em uma escola construtivista, situada em Belo Horizonte - Minas Gerais, em 2011. A escolha da escola ocorreu tendo em vista a crença dos autores deste artigo na capacidade de instituições construtivistas em fornecerem bases conceituais e teóricas para o uso das tecnologias a favor da construção do conhecimento nas relações sociais e no compartilhamento dos significados.

Primeiramente realizou-se uma pesquisa bibliográfica sobre a utilização das TDICs no processo de ensino e aprendizagem e os fundamentos da prática construtivista, que vai além dos conhecimentos construídos na escola. Em seguida, escolheu-se uma escola de proposta construtivista em seu projeto pedagógico para observar durante oito meses o processo de utilização de um ambiente virtual de aprendizagem (AVA) junto aos alunos do Ensino Médio, contemplando as seguintes categorias do projeto político pedagógico (PPP): fundamentos, currículo, competência e valores. O texto organiza-se em torno de discussão preliminar sobre a utilização das tecnologias no processo de construção do conhecimento, da análise do construtivismo como proposta que transcende a sala de aula e do estudo e reflexão sobre proposta de utilização de um AVA nas 
atividades de ensino-aprendizagem de disciplina optativa do Ensino Médio em uma escola construtivista.

\section{A proposta de utilização de um ambiente virtual de aprendizagem (AVA) em uma escola construtivista}

Durante o ano de 2011, observou-se à implantação do AVA em disciplina optativa do Ensino Médio denominada Edocomunicação e Atualidades, constituída de vinte e oito alunos e um professor. Cabe ressaltar que anualmente os alunos deste segmento têm doze disciplinas optativas, das quais devem escolher quatro, o que segundo o Projeto Político Pedagógico (PPP) de 2011 desta escola, enriquece e flexibiliza um currículo moderno e ousado.

A disciplina Edocomunicação está relacionada com um campo de reflexão e ação que une as áreas de Educação e Comunicação Social, traz o cotidiano da vida social e das tecnologias da informação e para os processos educacionais

$\mathrm{Na}$ linha de modernização das práticas pedagógicas, superando propostas consideradas enciclopedistas, a escola, além de garantir os preceitos legais da LDB, investe em propostas de educação tecnológica básica e fundamentos filosóficos e sociais do Ensino Médio, com vistas à formação de juventude questionadora e atuante na sociedade.

Para a compreensão dos diferentes discursos e concepções a respeito da realidade, a escola redefine o lugar da ciência na formação dos alunos como parte de um sistema de representações sociais em que não existem verdades absolutas e como parte do currículo disponibiliza a disciplina Iniciação Científica.

Dentre as competências desta disciplina, o PPP aponta que o aluno compreenda o desenvolvimento das tecnologias como resultado de processos econômicos, sociais e culturais vivenciados pela humanidade e reflita criticamente sobre o uso das tecnologias. Esta competência está vinculada à disciplina Edocomunicação e Atualidades, pois se espera desta que o aluno compreenda os processos de produção das diversas mídias como forma de desenvolver uma reflexão crítica sobre os efeitos da chamada indústria cultural.

Com o objetivo de trabalhar essas competências e de refletir sobre as transformações atuais trazidas pelas tecnologias, o professor da disciplina de 
Edocomunicação introduziu a plataforma Moodle ${ }^{5}$ em sua prática escolar durante o ano de 2011, o que para ele foi uma experiência pioneira, assim como para os alunos e para a escola. O professor escolheu essa plataforma devido a sua capacidade de comunicação entre professor e o grupo de alunos baseada na Web, facilitando os encontros mesmo como à distância, uma vez que a aula desta disciplina ocorria apenas uma vez por semana e também por ser um sofware livre, isto é, sem ônus financeiro para a escola.

Além disso, ele contou com o apoio do coordenador do Ensino Médio ${ }^{6}$, para o qual "o Moodle pode ser o gestor do curso, dado que apresenta muitas ferramentas e estratégias, até mesmo para avaliação. A escola precisa ter mais equipamentos sim, mas isso não vai nos amarrar, uma vez que temos uma ferramenta free para ajudar". Quanto aos benefícios para a aprendizagem e às possibilidades desta plataforma, Leite (2007) afirma que o Moodle possibilita, ao invés da transmissão, a construção do conhecimento a partir de trocas, mediações e interações e exige a ação do aluno como, por exemplo, responder e discutir.

Tais características de aula estão de acordo com o fundamento da escola investigada, consta no PPP que em vez de transmissão de conteúdos, busca-se o aluno no lugar de sujeito ativo. A ação do sujeito acontece devido às atividades do Moodle e suas possibilidades são apresentadas no quadro abaixo:

\section{Quadro 1: Esquema das possibilidades da Plataforma Moodle}

\begin{tabular}{|l|l|}
\hline Ferramenta & Possibilidades \\
\hline Fórum & $\begin{array}{l}\text { Todos podem ver o que todos fazem. Pode servir para: discussão de } \\
\text { temas relativos ao conteúdo (com mediação), Mini-blog (cada aluno } \\
\text { tem um tópico para criar sua página inicial), Wiki (construção de } \\
\text { texto de modo colaborativo), Mural (exposição de trabalhos), espaço } \\
\text { de reflexão coletiva ou discussão de texto, estudos de caso, } \\
\text { construção de trabalhos ou projetos etc. }\end{array}$ \\
\hline Chat & $\begin{array}{l}\text { Comunicação escrita síncrona, em tempo real, entre professores e } \\
\text { alunos. Pode ser um espaço para esclarecimento de dúvidas ou para } \\
\text { um bate-papo com um convidado. Ficam registrados para consultas } \\
\text { posteriores. }\end{array}$ \\
\hline Escolha & $\begin{array}{l}\text { Oportunidade aos alunos em escolher uma única opção entre uma } \\
\text { lista definida pelo professor a partir de uma pergunta. Podem ser } \\
\text { usadas em atividades como: coleta de opinião, identificação de um } \\
\text { conhecimento prévio sobre um tema específico, entre outras. }\end{array}$ \\
\hline Glossário & $\begin{array}{l}\text { É colaborativo, todos podem inserir itens. Os participantes podem } \\
\text { criar dicionários de termos relacionados com a disciplina, bases de }\end{array}$ \\
\hline
\end{tabular}

\footnotetext{
${ }^{5}$ MOODLE TRUST. Disponível em: <https://moodle.org/>. Acesso em: 18 jan. 2012.
}

${ }^{6}$ Fala do coordenador do Ensino Médio registrada durante a pesquisa. 


\begin{tabular}{|l|l|}
\hline & $\begin{array}{l}\text { dados documentais ou de arquivos e galerias de imagens ou links, que } \\
\text { podem ser facilmente pesquisados. }\end{array}$ \\
\hline Diário & $\begin{array}{l}\text { Permite que o aluno construa textos de reflexão ou síntese de } \\
\text { aprendizagem, que podem ser aperfeiçoadas continuamente. }\end{array}$ \\
\hline Questionário & $\begin{array}{l}\text { Permite elaborar questões com diferentes formatos de resposta (V ou } \\
\text { F, múltipla escolha, resposta curta etc). Pode importar questões de } \\
\text { arquivos txt. Permite responder o questionário diversas vezes, } \\
\text { aplicando ou não penalidades por tentativas. }\end{array}$ \\
\hline Tarefa & $\begin{array}{l}\text { Permite ao professor ler, avaliar e comentar as produções dos alunos. } \\
\text { As notas e/ou feedbacks ficam disponíveis para o conhecimento do } \\
\text { aluno e o professor pode exportar os resultados para planilha Excel. }\end{array}$ \\
\hline Wiki & $\begin{array}{l}\text { Permite a construção de um texto conjuntamente, com vários } \\
\text { participantes, onde todos podem editar e dar contribuições. É } \\
\text { obrigatório realizar em grupo ou em parceria. }\end{array}$ \\
\hline Lição & $\begin{array}{l}\text { É possível apresentar o conteúdo de forma atraente e flexível. } \\
\text { Atividade interessante para estudo autônomo. }\end{array}$ \\
\hline Base de dados & $\begin{array}{l}\text { Pode ser um repositório de vídeos, de recursos educativos, de papers } \\
\text { ou fotos, pesquisável e ordenável por categorias. }\end{array}$ \\
\hline
\end{tabular}

Fonte: Elaboração própria, baseado em Leite (2007).

Para conhecer e aprender a lidar com essas ferramentas, o primeiro passo realizado pelo professor foi participar de um curso a distância sobre a formação docente no trabalho com o Moodle. Este curso foi realizado na própria plataforma e ao terminá-lo, o professor afirmou ter aprendido sim sobre as possibilidades da plataforma, mas sentia ainda necessidade de aprofundar conhecimentos em relação ao AVA e acreditava na aprendizagem continuada no seu processo de trabalho com os alunos à medida que as aulas fossem acontecendo.

Vale ressaltar que durante a graduação em Comunicação Social o professor informou não ter participado de disciplina que abordasse o uso das tecnologias na escola, assim como a escola que ele leciona não promoveu durante o período trabalhado por ele nenhum curso, palestra ou debate sobre o assunto. "Essa formação dos professores, descontextualizada com o século XXI, prejudica e empobrece nossa prática pedagógica. Cabe ao educador criar suas próprias estratégias para alinhar o atual ao ensino", relatou o professor da disciplina de Edocomunicacão.

O segundo passo foi à implantação do AVA Moodle na escola. Este processo durou dois meses em vista da pouca familiaridade dos responsáveis técnicos em informatizar e lidar com essa tecnologia. Durante esse período de instalação, o professor apresentou aos alunos a proposta de utilizarem uma plataforma digital para expandir os momentos de encontro entre eles e conhecerem na prática o AVA. Segundo ele "a 
tecnologia mais do que nunca fará parte da vida acadêmica dos alunos, sendo possível cada um criar o seu tempo e ter autonomia para construir seus conhecimentos através das trocas e interações"7.

A autonomia é um dos valores apontados no PPP da escola, definida como consciência de si e do outro, como compreensão da existência de espaços a ocupar e limites a respeitar, além de independência e ética. Para Piaget (1977), a autonomia se desenvolve com o desenvolvimento da autoconsciência onde o indivíduo desloca o eixo de suas relações de si para o outro, substituindo a norma da autoridade pela norma da própria ação.

É justamente essa ação do aluno sobre o objeto de estudo que o professor esperava dos alunos ao utilizarem o Moodle, disponibilizado inicialmente fóruns e glossário, o que permitiria as trocas de experiências sobre como as tecnologias são utilizadas no mundo atual, o compartilhamento de antigos trabalhos de grupo sobre vídeos produzidos na escola e a discussão de outros assuntos relacionados à disciplina, mas não houve participação dos alunos.

Segundo uma das alunas, isso ocorreu devido à falta de tempo, para ela "criar uma plataforma para ensinar significa dar mais trabalho aos alunos e o tempo para isso é muito limitado diante da quantidade de tarefas a serem realizadas para outras disciplinas e o estudo para o ENEM"». Além disso, ela afirmou que "a maioria dos alunos tem rede social e esta já faz parte de nossa rotina para nos comunicarmos com amigos, colegas e parentes" e sugeriu "por que não utilizarmos o Facebook para nossas trocas ao invés do Moodle"?

Diante dessa nova proposta o professor pediu que realizassem a comparação entre o Moodle e o Facebook para que pudessem perceber as diferenças e semelhanças entre eles e verificar se o Facebook atenderia o objetivo de comunicação entre alunos e alunos e alunos e professor para além da escola. O interessante é que outro objetivo estava sendo alcançado, os alunos estavam refletindo sobre as possibilidades que a rede social poderia oferecer para o ensino.

\section{Considerações Finais}

\footnotetext{
${ }^{7}$ Fala do professor de Edocomunicação registrada durante a pesquisa.

${ }^{8}$ Fala da aluna de Edocomunicação registrada durante a pesquisa.
} 
Pôde-se verificar que a utilização das TDICs no processo de ensino e aprendizagem e os fundamentos da prática construtivista ultrapassam os conhecimentos construídos na escola, favorecendo a construção do conhecimento.

Assim, diante da utilização dessas tecnologias, professor e alunos perceberam, no caso especifico desta pesquisa, que o Facebook enquanto um exemplo de uma ferramenta tecnológica digital utilizada principalmente como uma rede social, permite criar grupo, postar vídeos, atividades e comentários, criar glossário e promover chats. Tais possibilidades se assemelham às do Moodle, mas à medida que acontecem as trocas e os comentários, estes não ficam registradas de maneira organizada como aconteceria no Moodle, pois um registro sobrepõe o outro e fica difícil retomar as informações para serem discutidas e aprofundadas no momento da aula presencial. Esta diferença justificase pelo fato do Moodle ser um software desenvolvido para auxiliar no processo de troca, voltado especificamente para o ensino e aprendizagem, o que não ocorre com o Facebook que é um software de comunicação. Contudo, mesmo com esta diferença, os envolvidos nesta experiência verificaram que a ferramenta de comunicação, no caso o Facebook, contribuiu para que ocorresse o aprendizado e a interação à possibilidade de interação entre sujeitos localizados em espaços físicos diferenciados, com o entre os alunos e o professor.

Quanto ao Ambiente Virtual de Aprendizagem (AVA) pode-se considerá-lo uma proposta educacional, no sentido de proporcionar uma aprendizagem colaborativa e mediada por diversos sujeitos sociais (como os alunos e professores) que atuam efetivamente para a construção do conhecimento, sem deixar de reforçar a noção de interatividade que deve estar sempre presente neste ambiente.

Portanto, este estudo de caso reforçou a crença dos autores deste artigo na capacidade de instituições que construtivistas em fornecerem bases conceituais e teóricas para o uso das tecnologias a favor da construção do conhecimento nas relações sociais e no compartilhamento dos significados, principalmente quando verificou-se, que os alunos conseguiram refletir sobre as possibilidades que uma rede social poderia oferecer para o ensino.

Também a pesquisa revelou alguns problemas no que se refere ao perfil construtivista da instituição, como na formação de professores, pois é necessário aos profissionais da educação formação para lidar com as tecnologias informacionais em um contexto de rápidos avanços e de intensas demandas sociais e para formar indivíduos capazes de atuar criticamente em ambientes de constantes reformulações. Além disso, 
observou-se dificuldades tecnológicas enfrentadas pela escola. Mas também é necessário ressaltar que a experiência foi acolhida de forma muito positiva pelos alunos e pelo professor e acredita-se que estes são problemas que estão e serão corrigidos ao longo da prática pedagógica da instituição. Pode-se, portanto, considerar que a experiência de aprendizagem utilizando AVA foi muito positiva e foi bem recebida pelos alunos e professores.

\title{
CONSTRUCTIVIST CONCEPTION PERMEATED BY THE USE OF THE TECHNOLOGY: A CASE STUDY
}

\begin{abstract}
Diferent technologies are present in school contexts, and depending on how they are used, they can promote the construction of knowledge. To understand how the constructivist conception can contribute to constructivist learning permeated by the use of technologies this paper investigated the impact of digital technologies of information and communication (TDICs) in the constructivist teaching practice, from a case study in a school constructivist of Belo Horizonte - Minas Gerais, using a virtual learning environment (VLE) in a elective discipline. It was found that the use of TDICs goes beyond the knowledge constructed in school, favoring the teaching and learning process. So the VLE can be considered an educational as it provides a learning collaborative and mediated by various social subjects that act effectively for the construction of knowledge.
\end{abstract}

KEYWORDS: Knowledge. Digital Technologies of Information and Communication (TDICs). Constructivism and pedagogical practice.

\section{REFERÊNCIAS}

BRASIL. Decreto-lei n ${ }^{\circ} .394$, de 20 de Dezembro de 1996. Estabele as diretrizes e bases da educação nacional. Brasília, 1996. Disponível em:

<http://www.planalto.gov.br/ccivil_03/Leis/L9394.htm>. Acesso em: 07 abr. 2013.

CARNEIRO, M. A. LDB fácil: leitura crítico-compreensiva artigo a artigo. Rio de Janeiro: Vozes, 1998.

COSCARELLI, C. V. Novas tecnologias, novos textos, novas formas de pensar. Belo Horizonte: Autêntica, 2002.

COSTA, J. W. Apresentação grupo de pesquisa: ambientes virtuais de aprendizagem. AVACEFET. Belo Horizonte, 2007. Disponível em: 〈http://www.avacefetmg.org.br〉. Acesso em: 16 dez. 2011.

COSTA, J. W.; PAIM, I. Informação e conhecimento no processo educativo. In: COSTA, J. W.; OLIVEIRA, M. A. M. (Org.). Novas linguagens e novas tecnologias: educação e sociabilidade. Petrópolis: Vozes, 2004. 
FONTANA, R.; CRUZ, N. Psicologia e trabalho pedagógico. São Paulo: Atual, 1997.

GOMES, P. V. A experiência da PUC-PR na implantação das tecnologias de informação e comunicação no ensino superior. Colabora, Curitiba, v.1, n.1, p.37-45, 2001.

GRINSPUN, M. P. S. Z. (Org.). Educação tecnológica: desafios e perspectivas. 3. ed. São Paulo: Cortez, 2002.

JONASSEN, D. O uso das novas tecnologias na educação a distância e a aprendizagem construtivista. Em aberto, Brasília, vol.16, n.70, abr./jun.,1996. Disponível em: <http://www.rbep.inep.gov.br/index.php/emaberto/article/viewfile/1054/956>. Acesso em: 24 mar. 2012.

LEITE, M. T. M. Relato de experiência: oficinas Moodle para docentes da UNIFESP. In: $13^{\circ}$ CONGRESSO INTERNACIONAL DE EDUCAÇÃO A DISTÂNCIA. 2007, Curitiba: Anais... Curitiba, 2007.

LÉVY, P. As tecnologias da inteligência: o futuro do pensamento na era da informática. Rio de Janeiro: 34, 1993.

MACEDO, L. Ensaios pedagógicos: como construir uma escola para todos? Porto Alegre: ARTMED, 2005.

MENDONÇA, L. F. F. O que pensam os docentes sobre o uso das tecnologias da informação e da comunicação nas práticas de ensino? Rio de Janeiro: UFRJ, 2010. Disponível em: <www.abed.org.br/ congresso2010/ed/352010004454.pdf〉. Acesso em: 18 jan. 2012.

MOORE, N. A sociedade da informação. In: INSTITUTO BRASILEIRO DE INFORMAÇÃO EM CIÊNCIA E TECNOLOGIA. A informação: tendências para o novo milênio. Brasília: IBICT, 1999.

MORAN, J. M. Educação inovadora presencial e a distância. São Paulo: Loyola, 2003. Disponível em: <www.eca.usp.br/prof/moran/inov_1.htm>. Acesso em: 18 dez. 2011.

OLIVEIRA, C. C; COSTA, J. W.; MOREIRA, M. Ambientes informatizados de aprendizagem. In: COSTA, J. W.; OLIVEIRA, M. A. M. (Org.). Novas linguagens e novas tecnologias: educação e sociabilidade. Petrópolis: Vozes, 2004.

PEROZIN, L. A "bola" da vez. Carta Capital, [S.1.] 2011. Disponível em: <http://www.cartacapital.com.br/carta-fundamental/a-bola-da-vez>. Acesso em: 20 dez. 2011.

PIAGET, J. A teoria de Jean Piaget e a educação. In: MILLAN, W. (Org.). Psicologia e ensino. São Paulo: Papelivros, 1980.

PIAGET, J. O julgamento moral na criança. São Paulo: Mestre Jou, 1977.

REZENDE, F. As novas tecnologias na prática pedagógica sob a perspectiva construtivista. Ensaio - Pesquisa em Educação em Ciências, Belo Horizonte, vol.2, n.1, 
2002. Disponível em: 〈http://www.fae.ufmg.br/ensaio/v2_n1.pdf>. Acesso em: 19 jan. 2012.

TAPSCOTT, D. A hora da geração digital. Rio de Janeiro: Agir Negócios, 2010.

TEPEDINO, S. A. S. A autoformação do professor para uso de tecnologias digitais na educação. 2004. 103f. Dissertação (Mestrado em Educação) - Pontifícia Universidade Católica de Minas Gerais, Belo Horizonte, 2004.

SILVA, I. M. M. Múltiplos papéis dos professores na educação a distância e práticas de letramento digital. Recife: Ed. da UFRPE, 2009

VYGOTSKY, L. A formação social da mente. São Paulo: Martins Fontes, 2007.

WEINBERG, M. Medir para avançar rápido. Revista Veja, São Paulo, n.6, p.17-21, 2008. 